\title{
Cytotoxic T lymphocyte responses against melanocytes and melanoma
}

\author{
Gwendolen Y Chang ${ }^{1}$, Holbrook E Kohrt ${ }^{1}$, Tor B Stuge ${ }^{1}$, Erich J Schwartz ${ }^{2}$, Jeffrey S Weber ${ }^{3}$ and Peter P Lee ${ }^{1 *}$
}

\begin{abstract}
Background: Vitiligo is a common toxicity associated with immunotherapy for melanoma. Cytotoxic T lymphocytes (CTLs) against melanoma commonly target melanoma-associated antigens (MAAs) which are also expressed by melanocytes. To uncouple vitiligo from melanoma destruction, it is important to understand if CTLS can respond against melanoma and melanocytes at different levels.

Methods: To understand the dichotomous role of MAA-specific CTL, we characterized the functional reactivities of established CTL clones directed to MAAs against melanoma and melanocyte cell lines.

Results: CTL clones generated from melanoma patients were capable of eliciting MHC-restricted, MAA-specific lysis against melanocyte cell lines as well as melanoma cells. Among the tested HLA-A*0201-restricted CTL clones, melanocytes evoked equal to slightly higher degranulation and cytolytic responses as compared to melanoma cells. Moreover, MAA-specific T cells from vaccinated patients responded directly ex vivo to melanoma and melanocytes. Melanoma cells express slightly higher levels of MART-1 and gp100 than melanocytes as measured by quantitative reverse-transcriptase polymerase chain reaction (qRT-PCR) and immunohistochemistry.
\end{abstract}

Conclusions: Our data suggest that CTLs respond to melanoma and melanocytes equally in vitro and directly ex vivo.

\section{Introduction}

Recent FDA approval of ipilimumab for metastatic melanoma provides strong support for the ability of the immune system to mediate a beneficial effect against this disease. However, immunotherapies for melanoma, including ipilimumab [1] and adoptive cellular therapies [2], come with substantial toxicities, including vitiligo [3-5], ocular [6] and systemic autoimmunity [1]. As such, a major need in next-generation melanoma immunotherapy is to uncouple tumor immunity from autoimmunity [7]. To improve the functional effectiveness of melanoma-reactive CTLs, understanding the factors leading to recognition of self and the barriers to breaking immune tolerance is crucial.

Two decades ago, pioneering work from the Rosenberg [8] and Boon [9] groups first demonstrated that $\mathrm{T}$ cells infiltrating human melanoma often target self, nonmutated proteins that are also expressed by normal

\footnotetext{
* Correspondence: ppl@stanford.edu

'Department of Medicine, Division of Hematology, Stanford University

School of Medicine, Stanford, California, USA

Full list of author information is available at the end of the article
}

melanocytes. These include enzymes in the biosynthesis of melanin, such as MART-1, gp100, and tyrosinase [10]. How these self tumor-associated antigens (TAAs) elicit $\mathrm{T}$ cell responses in the context of melanoma remains unclear. It is suggested that TAAs are overexpressed in melanoma cells, thus eliciting responses by low avidity TAA-specific $T$ cells that escape central deletion $[11,12]$. If true, this offers an opportunity to target melanoma without harming normal melanocytes by specifically eliciting low avidity TAA-specific T cells [13].

In this study, we address whether CTLs respond to and target melanoma cells and normal melanocytes differently. We utilized a set of MART- or gp100-specific CTL clones that were determined to be high, intermediate, or low avidity (recognition efficiency, RE) based on peptide titrations. We assessed both CTL degranulation via mobilization of $\mathrm{CD} 107$, an integral membrane protein within cytolytic granules [14-16], and target cell killing via chromium release assays. We also determined if target cells express the cognate TAAs at similar levels, and relate these to cytotoxicity.

\section{Biomed Central}




\section{Materials and methods Effector Cells}

CTL clones were generated using protocols as previously described [17]. Briefly, samples were obtained from four different patients (the patients were anonymously identified by numbers as "476", "422", "462", "520") with resected stage III or IV melanoma patients under informed consent approved by the institutional review boards of the National Cancer Institute (NCI; Bethesda, Maryland) and the Los Angeles County/University of Southern California; sample analysis was performed under protocols approved by the institutional review board of Stanford University. Peripheral blood mononuclear cell (PBMC) samples were obtained from patients after vaccination with melanoma-associated antigens (MAA) peptides MART 26-35 (27L) (ELAGIGILTV) and gp100 209-217 (210M) (IMDQVPSFV) at the University of Southern California Norris Cancer Center (Los Angeles, California). The samples were analyzed by FACS for MAA-specific T cells using HLAA*0201/peptide tetramer-phycoerythrin (PE) made with MART A26 or gp100 209-217 (Beckman Coulter). Recognition efficiency and cytolytic capability of each CTL clone was determined as previously described $[15,17]$.

\section{Target Cells}

Melanoma cell lines Malme-3M, MeWo, A375 and the T2 cell line were purchased from American Type Culture Collection (ATCC, Manassas, Virginia), and mel526 was obtained from the Surgery Branch of NCI. Melanocyte line HeMn-MP 4C0197 was purchased from Cascade Biologics (Portland, Oregon), and lines HeMn-LP and HeMn-MP with lot numbers 3C0523, 3C0527, 3C0651, 3C0659, 3C0764, and 3C0661 were kindly provided by Dr. Gary Shipley (Cascade Biologics). HLA-A*0201 status was tested in each melanocyte lot using direct PCR by the Stanford Histocompatibility Laboratory (Stanford, CA). T2 cells were pulsed and washed with either one of the MAA peptides, MART 26-35 or gp100 209-217, at a concentration of $10 \mu \mathrm{g} / \mathrm{mL}$ for 1 hour in $7 \% \mathrm{CO}_{2}$ prior to each assay.

\section{CD107 Mobilization Assay}

All assays were done in duplicates with an effector to target (E:T) ratio of $1: 1,2 \times 10^{5}$ of CTLs and $2 \times 10^{5}$ target cells in each well of 96 -well plates. T2 cells were prepared as described above. The following was added each well in order: $1 \mu \mathrm{l}$ of $2 \mathrm{mM}$ monensin (Sigma, St. Louis, Missouri) in 100\% EtOH, $100 \mu \mathrm{l}$ of target cells, $100 \mu \mathrm{l}$ of effector cells and $1 \mu \mathrm{l}$ each of CD107a-allophycocyanin (APC) and CD107b-APC antibodies (Abs). The cells are mixed well using a multichannel pipettor and brought into contact by centrifugation at $1000 \mathrm{rpm}$ for $1 \mathrm{~min}$. Effectors and targets were incubated at $37^{\circ} \mathrm{C}$ in $7 \% \mathrm{CO}_{2}$ for 4 hours. After the incubation, the plates were centrifuged at $1100 \mathrm{rpm}$ for $1 \mathrm{~min}$ to pellet cells, and the supernatant was removed. Cell-cell conjugates were disrupted by washing the cells using $1 \mathrm{x}$ PBS with $0.02 \%$ sodium azide and $0.5 \mathrm{mM}$ EDTA.

\section{Flow Cytometric Analysis}

After incubation with CD107 Abs, cells were washed and further stained with anti-human CD8-FITC (Caltag Laboratories, Burlingame, California; dilution of 1:200) and CD19-CyChrome (Becton Dickinson, San Jose, CA; dilution of 1:80). Cells were incubated for 1 hour at $4^{\circ} \mathrm{C}$ and were washed twice before analysis. Cells were analyzed using a two-laser, four-color FACSCalibur (Becton Dickinson). A minimum of 30,000 events were acquired and analyzed using Flowjo (TreeStar, San Carlos, California). Lymphocytes were identified by forward and side scatter signals, then selected for CD8 positivity and CD19 negativity. Gated cells were plotted for CD107 verses CD8 to determine level of $\mathrm{T}$ cell degranulation. Gates were analyzed for number and percentage of cells.

\section{Chromium Release Cytotoxicity Assay and Determination of Recognition Efficiency}

Cytotoxicity was measured in a standard ${ }^{51} \mathrm{Cr}$ release assay and all experiments were done in triplicates for each condition. Briefly, target cells were labeled with ${ }^{51} \mathrm{Cr}$ for overnight at $37^{\circ} \mathrm{C}$ in $7 \% \mathrm{CO}_{2}$. T2 cells were pulsed with peptides in conditions described above. Effectors were incubated with targets at a ratio of 10:1 (E:T) for 4 hours, and chromium release was measured. Percent cytotoxicity was calculated using the mean of the triplicates. Cytotoxicity of each CTL clone is expressed by $\%$ specific lysis $\pm \%$ std dev. To determine the recognition efficiency (RE), chromium-labeled T2 targets were pulsed with a range of native peptide concentrations, generally starting at $10^{-6} \mathrm{M}$ and decreasing by log steps to $10^{-14} \mathrm{M}$. For each CTL clone, percent cytotoxicity was plotted against peptide concentration and the negative log of the concentration. The peptide concentration at which the curve crossed $40 \%$ cytotoxicity was recorded as the RE of that clone. All assays were done twice.

\section{Quantitative Reverse-transcriptase Polymerase Chain Reaction (qRT-PCR)}

RNA from melanocytes, melanoma cells and unpulsed T2 were extracted as previously described [18]. cDNA synthesis was performed according to the manufacturer's protocol using Superscipt II reverse transcriptase (Invitrogen, Carlsbad, California) primed with oligo-dT. Oligonucleotide primers used in $\mathrm{qRT}$-PCR were synthesized based on 
published MART-1 and gp100 primer sequences [19]. Both primers were synthesized commercially by Elim Biopharmaceuticals (Hayward, California); the primer sequences are as follows: gp100(S): 5'-AGTTCTAGGGG GCCCAGTGTCT-3', (AS): 5'-GGGCCAGGCTCCAGGTAAGTAT-3'; MART-1 (Melan-A)(S):5'-TGACCCTACAAGATGCCAAGAG-3', (AS): 5'-ATCATGCATTGCA ACATTTATTGATGGAG-3'. The real-time qRT-PCR was performed in single wells of a 96-well plate (BioRad, Hercules, California) in a $25 \mu \mathrm{l}$ reaction mixture using components of the Sybr Green qPCR system according to manufacturer's protocol (Invitrogen). Cycling of cDNA involved denaturation at $95^{\circ} \mathrm{C}$ for $30 \mathrm{~s}$, annealing at $50^{\circ} \mathrm{C}$ for $1 \mathrm{~min}$ and extension at $70^{\circ} \mathrm{C}$ for $1 \mathrm{~min}$ for 40 cycles using the $\mathrm{iCycler}_{\mathrm{iQ}}^{\mathrm{TM}}$ (BioRad). Fluorescence was measured following each cycle and displayed graphically (iCycler iQ Real-time Detection System Software, version 2.3, BioRad). The software determined a cycle threshold (Ct) value, which identified the first cycle at which the fluorescence was detected above the baseline for that sample or standard. The Ct value of MAA divided by Ct value of glyceraldehyde-3-phosphate dehydrogenase, an internal control, to express the relative ratio of mRNA expression in each cell line. Each qRT-PCR was performed in duplicate and data represents the mean of the duplicate of relative ratio in each condition.

\section{Immunohistochemistry}

Formalin-fixed paraffin-embedded sections were obtained from primary or metastatic tumors and surrounding skin biopsies of patients with malignant melanoma in accordance with protocols approved by Stanford University. Monoclonal antibodies to Melan-A and gp100 (HMB45) were purchased from DAKO (Carpinteria, CA) and immunohistochemistry was carried out following the manufacturer's recommended conditions. Samples were analyzed in the Department of Pathology by a single pathologist (EJS). The extent of staining was scored as percentage of melanocytes or malignant cells testing positive for the presence of either Melan-A or gp100. Each patient sample was then assigned to one of three groups: $<5 \%, 5-20 \%,>20 \%$.

\section{Statistical analysis}

Data are presented as mean \pm standard error of mean. Two-tailed Student's T-test was used where appropriate with significance defined at $\mathrm{p}<0.05$. Standard linear regression analysis was used to determine correlation between degranulation and cytotoxicity assays.

\section{Results}

HLA-A2 Characterization of Target Cells and Recognition Efficiencies of Effector Cells

HLA-A*0201 status of each melanocyte cell line was analyzed using PCR-based analysis (Table 1). Melanocyte
Table 1 Summary of HLA-A2 status in neonatal melanocyte lines

\begin{tabular}{lc}
\hline Melanocyte Line & HLA-A2 status \\
\hline 3 C0651 & (-negative) \\
\hline 3 C0659 & $\begin{array}{l}\text { (-positive) A2*0202 } \\
\text { (-positive) A2*0263 }\end{array}$ \\
\hline $3 C 0764$ & (-negative) \\
\hline $3 C 0661$ & (-positive) A2*0201 \\
\hline $4 C 0197$ & (-positive) A2*0201 \\
\hline
\end{tabular}

lines 4C0197 and 3C0661 are HLA-A*0201-positive, while 3C0659 expresses two different alleles (HLA-A*0202/ 0263) and 3C0764 is HLA-A2 negative. Melanoma lines Malme-3M, mel526, and MeWo are HLA-A*0201-positive and express MAAs gp100, MART-1, and tyrosinase. A375 is also a HLA-A*0201-positive melanoma line but is defective in intracellular processing and MHC presentation of gp100, MART-1, and tyrosinase [20]. MART-1 and gp100 specific CTL clones were previously isolated from PBMC samples of four post-vaccinated melanoma patients [15-17]. Antigen specificity and recognition efficiency (RE) of each clone are summarized in Table 2.

\section{CTL Degranulation Upon Contact with Melanocytes Compared to Melanoma Cells}

To examine CTL degranulation in the presence of melanocyte or melanoma cells, flow cytometric quantification of surface mobilization of CD107, an integral membrane protein in cytolytic granules, was employed using previously established protocol [14-17]. Functional reactivities of gp100 and MART-1 specific CTL clones in the presence of melanocyte lines HEMn-4C0197, 3C0661, $3 \mathrm{C} 0659$, and $3 \mathrm{C} 0764$ were compared with that in presence of melanoma lines A375, mel526, and Malme-3M using the CD107 degranulation assay. Two representative CD107 mobilization FACS assays are plotted in Figure 1, showing CTL degranulation of a high RE and an intermediate RE gp100-specific clone (Figure 1).

Mean percent degranulation of six tested clones, three gp100-specific (A) and three MART-1-specific (B), of high, intermediate or low RE, are plotted against each target cell line in Figure 2. For the high RE, gp100-specific CTL clone, degranulation was $~ 90 \%$ to both A2-positive melanocyte lines, versus $60-80 \%$ to melanoma lines Malme-3M, mel526, and MeWo (Figure $2 \mathrm{~A}$ ). This represents a modest but significant difference $(\mathrm{p}=0.02)$. Both MART-1 and gp100-specific CTL clones of high avidity demonstrated a moderate level (25-39\%) of CD107 degranulation against 3C0764 (HLA-A2 negative) and 3C0659 (HLA-A*0202/0263) melanocyte lines (Figure 2A and 2B, top panels). For the other clones, degranulation to A2-positive melanocytes and melanoma cells were to similar levels, with 
Table 2 Characterization of MART-1 and gp100 - specific CTL clones by recognition efficiency

\begin{tabular}{|c|c|c|c|}
\hline MAA specificity & Clone & RE for native peptide (-log of peptide concentration, M) & Functional Avidity \\
\hline \multirow[t]{3}{*}{ gp100 } & 476.140 & 11.2 & high \\
\hline & 422.50 & 10.4 & intermediate \\
\hline & 476.105 & 8.3 & low \\
\hline \multirow[t]{3}{*}{ MART-1 } & 461.24 & 7.7 & high \\
\hline & 520.18 & 7.2 & intermediate \\
\hline & 520.31 & 5.1 & low \\
\hline
\end{tabular}

trends toward slight increases against melanocytes than melanoma $(\mathrm{p}=0.1-0.15)$.

\section{Lymphocytes From Vaccinated Patients Are Reactive Against Melanocytes Ex Vivo}

Two PBMC samples isolated from peptide-vaccinated patients were tested and found to be capable of eliciting HLA-/MAA-specific degranulation against both HLA-
A*0201-positive melanocytes and melanoma directly ex vivo (Figure 3 ). Of CD8+ T cells, $0.2-0.5 \%$ were gp100 pMHC tetramer-positive (Figure 3). Amongst pMHC tetramer + CD8 $+\mathrm{T}$ cells isolated from patient 10820, 0\% degranulated against antigen-deficient melanoma A375, $11 \%$ degranulated against $\mathrm{A} * 0201$-positive melanocytes, $15 \%$ and $16 \%$ degranulated against melanoma lines Malme3M and mel526. For patient 10839, 1\%, 59\%, 24\%,

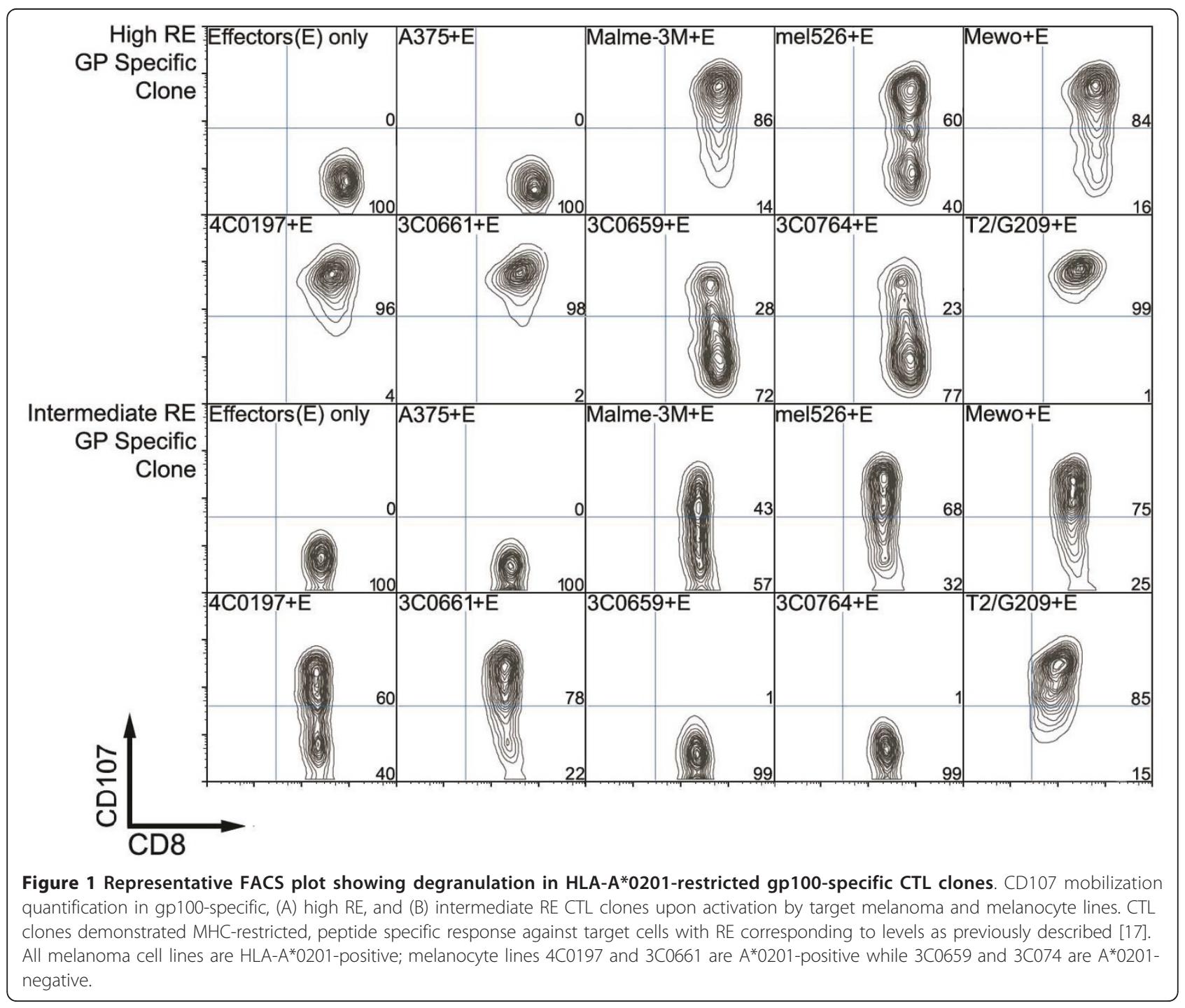




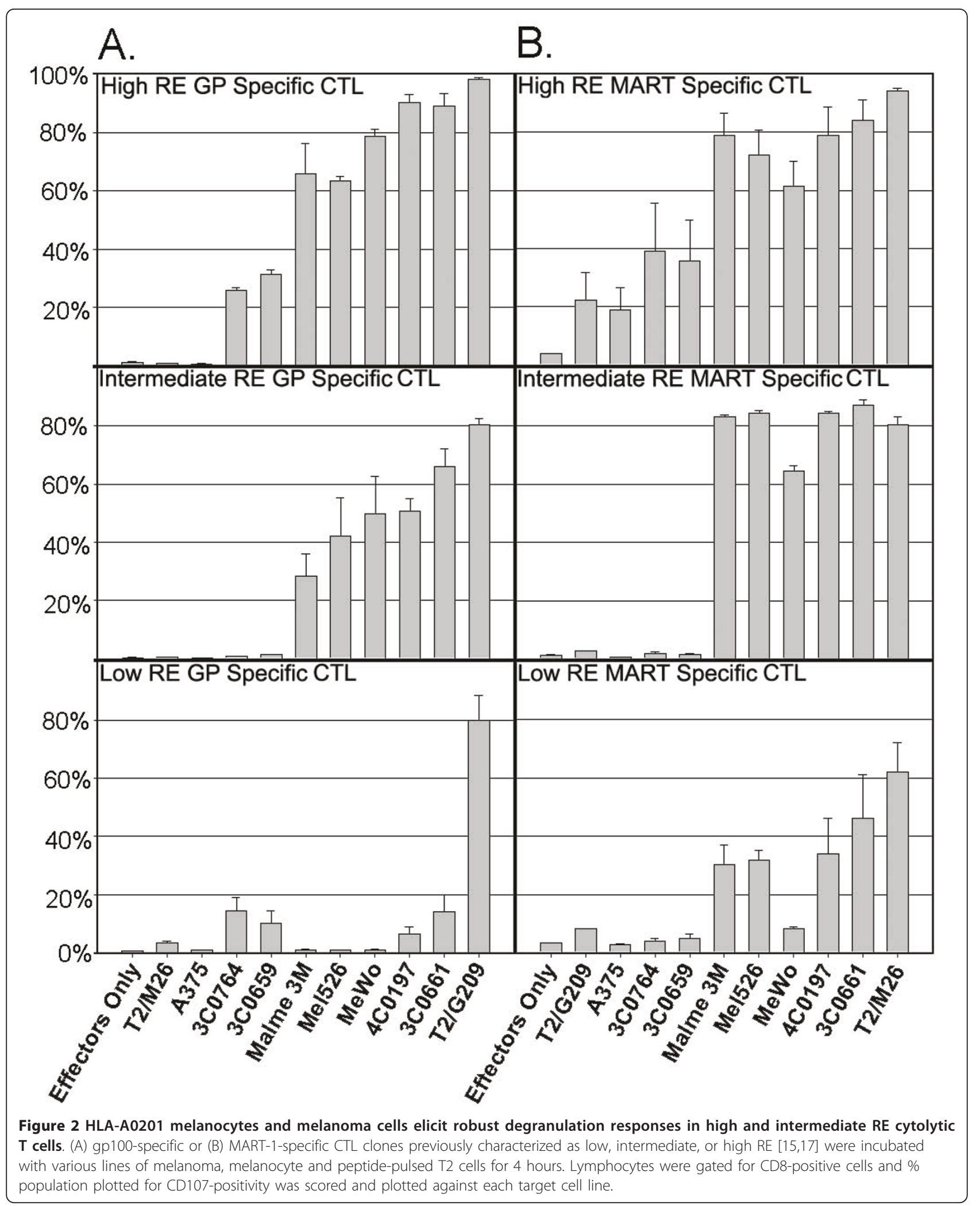




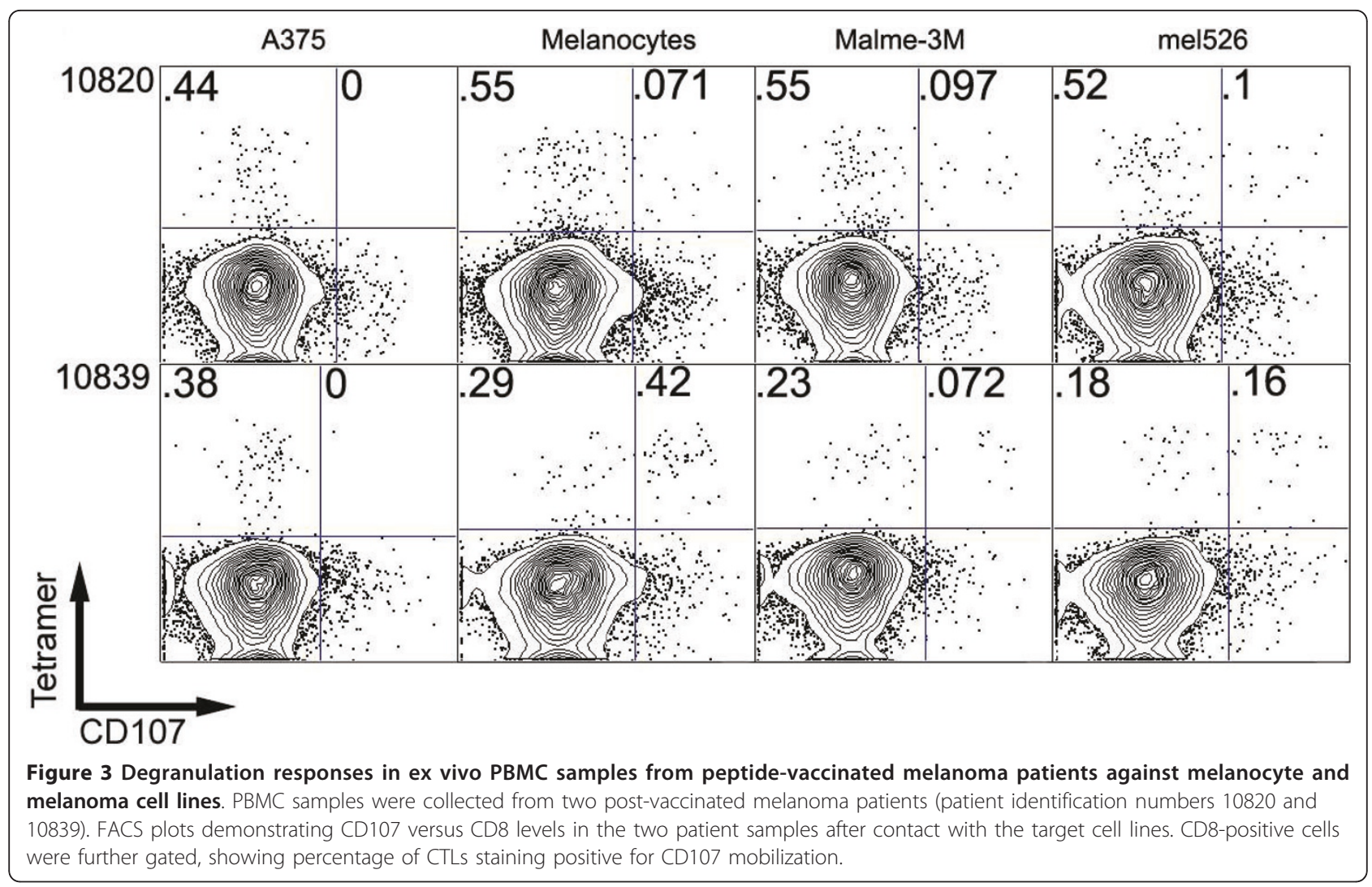

and $47 \%$ of CD $8+$ tetramer+ $\mathrm{T}$ cells degranulated against A375, A2-positive melanocytes, Malme3M, and mel526, respectively. These results suggest that peripheral blood CTLs from vaccinated patients are reactive against both melanoma and melanocytes directly ex vivo, at similar extents.

\section{Melanocytes are Equally Prone To CTL-Mediated Lysis as Melanoma Cells}

All CTL clones were functional and specific as demonstrated by lysis of $\mathrm{T} 2$ cells presenting relevant or irrelevant peptides (Figure 4). CTL lysis was HLA-restricted and antigen-specific, as HLA-A2 unmatched melanocytes and antigen-deficient melanoma line A375 had low cytotoxicity, ranging from $0-10 \%$. For MART-specific clones, cytotoxicity reached $80-90 \%$ against $\mathrm{A}^{*} 0201$-positive melanocyte lines compared to $40-80 \%$ against A2-positive melanoma lines by high RE clones $(\mathrm{p}=0.19)$, and $40-50 \%$ against melanocytes versus $15-25 \%$ against melanoma cells by intermediate RE clones ( $\mathrm{p}=0.02)$. For gp100specific clones, cytotoxicity was $70-90 \%$ against melanocytes versus $35-60 \%$ against melanoma $(\mathrm{p}=0.08)$ by high RE clones, and $18-40 \%$ against melanocytes versus 15 $25 \%$ against melanoma cell lines $(\mathrm{p}=0.6)$ by intermediate $\mathrm{RE}$ clones. Low RE clones had little to no cytotoxicity $(<20 \%)$ against melanoma or melanocytes, even though they had robust (95-100\%) lysis against T2 pulsed with the relevant peptide. These data represent a modest but not statistically significant increase in CTL-mediated lysis of melanocytes compared to melanoma, with the exception of the intermediate RE, MART-specific clone. A robust correlation $\left(r^{2}=0.80-0.88\right)$ was shown to exist between the degree of cytolytic activity and degranulation against various target cells, consistent with our previous results establishing CD107 mobilization as both an indicator of functional RE and target susceptibility $[15,17,21]$.

\section{Quantification and Comparison of Melanoma-Associated Antigen Expression In Melanocytes Versus Melanoma Cells}

To examine if an increased level of MAA expression underlies the strength of CTL-target interaction, we employed qRT-PCR in examining whether the amount of MAA mRNA may correlate with the extent of CTL degranulation and cytotoxicity. A minor difference was seen between the levels of MART-1 and gp100 mRNA expression in melanocyte and melanoma cells (Table 3 ). In HLA-A2-positive melanoma cells, MART-1 expression is 1.23 -fold and gp100 expression is 1.11-fold higher than those expressed in $\mathrm{A}^{*} 0201$-positive melanocytes $(\mathrm{p}<$ 0.015). In addition, skin biopsies from melanoma patients were analyzed by a semi-quantitative approach to 


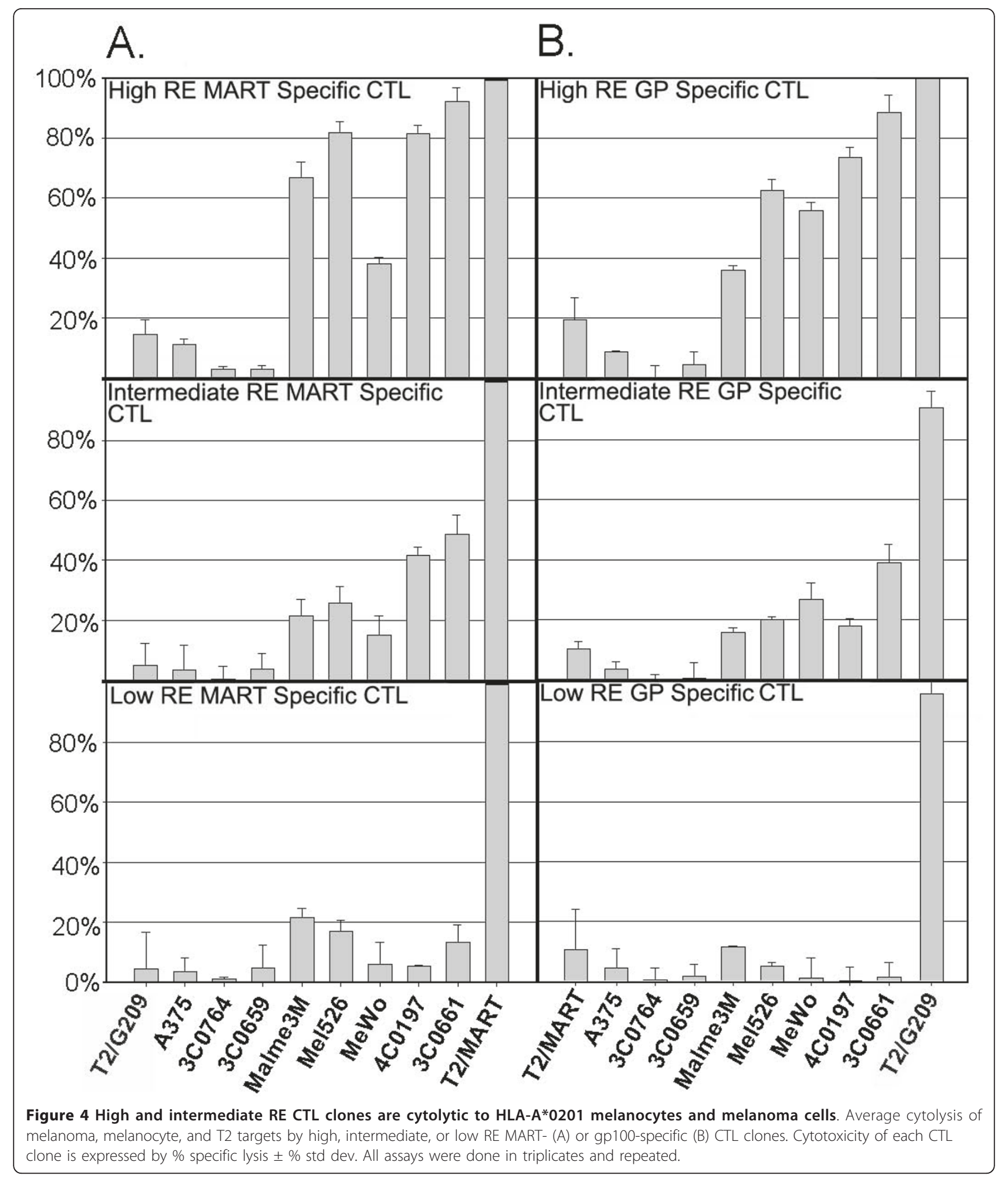

characterize surface MAA presentation in both benign and malignant tissue. As shown in Table 4, expression of both MART-1 and gp100 was variable in each of the samples. However, 3 out of the 5 samples (Cases 2, 3, and 5) expressed comparable amounts of MAAs in both melanocyte and melanoma clusters. In most cases (Cases 2-5), $>20 \%$ of both melanocytes and melanoma cells expressed MART-1. 
Table 3 Relative ratio of TAA mRNA expression in each target cell compared to glyceraldehye-3-phosphate dehydrogenase

\begin{tabular}{lccccccccccc}
\hline Target Cell Antigen & A375 & Malme3M & MeWo & Mel526 & 4C0197 & 3C0661 & 3C0659 & 3C0764 & T2 & water \\
\hline MART-1 & 0 & 1.225 & 1.21 & 1.315 & 1.035 & 1.06 & 1.085 & 1.08 & 0 & 0 \\
\hline gp100 & 2.295 & 1.285 & 1.225 & 1.3 & 1.195 & 1.115 & 1.23 & 1.175 & 0 & 0 \\
\hline GAPDH & 1 & 1 & 1 & 1 & 1 & 1 & 1 & 1 & 1 & 0 \\
\hline
\end{tabular}

\section{Discussion}

Autoimmunity against melanocytes has been observed to correlate with better clinical outcomes in malignant melanoma patients both anecdotally and in clinical trials of immunotherapies [8,11,22-25]. Can this treatment-related toxicity be uncoupled from anti-tumor activity? In this study, to examine the association between tumor killing and autoimmunity, MAA-specific CTLs were tested for degranulation and cytolysis against melanocyte and melanoma targets. MART-1 and gp100-specific CTL clones of high RE responded against melanocytes and melanoma targets, with a trend toward higher reactivity against melanocytes than melanoma. High avidity HLA-A*0201-specific clones non-specifically degranulate against $A^{*} 0201$-negative melanocyte lines at low levels insufficient for killing.

To address the notion that melanoma cells overexpress MAAs and may be preferentially targeted by lower RE CTLs that escape thymic deletion, we also analyzed reactivity patterns of intermediate and low RE CTL clones. Intermediate RE, MAA-specific CTLs responded comparably or slightly higher against melanocytes than melanoma cells. Low RE, MAA-specific CTLs showed little to no response against melanocytes and melanoma cells, even though they robustly lysed T2 cells pulsed with relevant peptide. Thus, these data argue against a previously held notion that low RE, MAA-specific CTLs can preferentially target

\section{Table 4 Immunohistochemistry staining for MART and gp100 in melanoma and melanocyte clusters in 5 melanoma patient cases ${ }^{\#}$}

\begin{tabular}{|c|c|c|c|c|c|c|c|}
\hline \multirow[t]{2}{*}{ Case } & \multirow[t]{2}{*}{ Diagnosis } & \multicolumn{3}{|c|}{ MelanA } & \multicolumn{3}{|c|}{ gp-100 (HMB45) } \\
\hline & & $20 \%$ & $5-20 \%$ & $<5 \%$ & $>20 \%$ & $5-20 \%$ & $<5 \%$ \\
\hline \multirow[t]{2}{*}{1} & NA & & & & & & \\
\hline & Melanoma (SS) & * & & & & & * \\
\hline \multirow[t]{2}{*}{2} & IDN & * & & & & & * \\
\hline & Melanoma (recur) & * & & & & & * \\
\hline \multirow[t]{2}{*}{3} & JMN & * & & & * & & \\
\hline & Melanoma (SS) & * & & & $*$ & & \\
\hline \multirow[t]{2}{*}{4} & IDN & $*$ & & & & & * \\
\hline & Melanoma (SS) & * & & & $*$ & & \\
\hline \multirow[t]{2}{*}{5} & IDN & * & & & & & * \\
\hline & Melanoma (Nevoid) & * & & & & & * \\
\hline
\end{tabular}

\#samples are scored based on percentage of melanocytes or malignant cells which stained histologically positive for either MelanA (MART-1) or gp100 in a given skin sample. melanoma cells and not normal melanocytes. Rather, these data suggest that MAA-specific CTLs respond against melanoma and melanocytes equally in vitro. This is consistent with a study showing melanoma lysis by vitiligo lesioninfiltrating CTLs [26]. This is not limited to in vitro expanded CTL clones, but also in directly ex vivo CTLs from patients post-vaccination. Technical challenges imposed by limited patient samples and low proportions of tumor-specific CTLs in the PBMC do not allow for a more detailed analysis or direct comparison to our in vitro observations. However, by selecting $\mathrm{pMHC}$ tetramer+, CD8+ T cells which represent MART-1 or gp100-specific CTLs, we observed similar levels of degranulation from these ex vivo CTLs upon contact with HLA-A2 melanocytes as compared to HLA-A2 melanoma cells.

In this study, there is a trend towards a lower degranulation efficiency of MART-1 specific clones against T2 target cells pulsed with MART peptides, when compared to gp100-specific clones against T2 pulsed gp100 peptides. In our previous studies, the RE scores observed for MART-1 specific clones presented with MART peptides were at a relatively lower range compared to clones presented with other peptides [15-17]. We hypothesize that this is likely due to the short predicted half-life of MART peptides (native and heteroclitic) in complex with the HLA-A*0201 molecule. Moreover, Rubio-Godoy et al. [27] found discrepancy between CTL effector functions measured by cytokine secretion and target cell lytic activities in their tyrosinase-specific clones. In their study, T cell clones detected by IFN- $\gamma$ ELISPOT but not detectable by pMHC multimer staining were able to lyse tyrosinase peptidepulsed target cells as efficiently as those stained by pMHC multimers. The authors attributed such differences to the kinetics of pMHC-multimer interaction with TCR among the clones studied. We speculate that while the lower degranulation efficiency correlates to the low RE observed for our MART-1 specific clone as expected, the high cytotoxicity observed may be a reflection of co-stimulation of other cytokine production such as IFN- $\gamma$ following CD107 degranulation.

Vaccine immunotherapy for melanoma can be associated with autoimmune effects of vitiligo. The incidence of vitiligo in patients with melanoma, although rare, is estimated to be seven to ten-fold higher than the general population [28]. The occurrence of vitiligo in melanoma patients undergoing immunotherapy may be due to both 
qualitative and quantitative differences between the CD8+ $\mathrm{T}$ cells in the two diseases. In a murine model by Steitz et al. [29], there appeared to be a two-step requirement for MAA-specific CD8+ T cells to break tolerance in the development of vitiligo. First, the stimulation and expansion of MAA-specific CD8+ T cells requires CD4+ T cell help in vivo during the "induction phase". Then, in the "effector phase", the CD8+ T cells require a strong local inflammatory stimulus for autoimmune destruction of melanocytes within the skin. Garbelli et al. [4] also reviewed data supportive of a qualitative difference between MAA-specific T cell responses in vitiligo and melanoma. In the several studies reviewed, CD8+ T cells isolated from vitiligo lesions or patients were found to have augmented functional avidity than those from their melanoma counterparts.

From a quantitative standpoint, incidence of vitiligo may be rare due to the low percentages of functional CTLs against melanoma antigens in the peripheral blood after vaccination. Our data is largely similar to what had been observed in other published studies. In study by Jacobs et al. [30], the authors found that when vitiligo occurs, MAA-specific CD $8+\mathrm{T}$ cells were observed in high percentages in both tumor and vitiligo lesions, supportive of the hypothesis that vitiligo may not be uncoupled from anti-tumor effect, and even indicative of the success of immunotherapy. However, only $<0.2 \%$ of the peripheral lymphocyte isolated from the studied patient demonstrated MAA-specific tetramer staining. In this study, $<0.6 \%$ of peripheral blood lymphocytes from our post-vaccinated patient samples demonstrated MAA-specific activity.

It is suggested that target recognition by CD8 $\mathrm{T}$ cells is dependent upon a critical threshold amount of $\mathrm{MHC} /$ MAA peptide expression on the cell surface [31-33]. Studies have shown that MAA expression may be highly variable across various clinical stages and different melanoma samples [34-36], with tumor escape from immune recognition achieved by loss of MAA or MHC expression [36-40]. Our data suggest that melanocytes and melanoma cells express MAAs at or above the recognition thresholds of high RE CTLs, as these effectors lysed both targets equally even though melanoma cells express the relevant MAAs at slightly higher levels. In contrast, for intermediate and low RE CTLs, lysis of melanoma and melanocytes was substantially below lysis of T2 pulsed with excess peptide. As such, increasing MAA expression levels specifically in melanoma cells, in context of immunotherapy with intermediate and low RE CTLs may be a possible avenue to uncouple tumor immunity from autoimmunity.

\section{Conclusions}

Among the tested HLA-A*0201-restricted CTL clones in this study, melanocytes evoked equal to slightly higher degranulation and cytolytic responses as compared to melanoma cells. Furthermore, MAA-specific T cells from vaccinated patients responded directly ex vivo to melanoma and melanocytes equally. These results suggest that CTL recognition and killing of melanoma may not be differentiated from autoimmune cytotoxicity of normal melanocytes.

\section{Acknowledgements}

We are grateful to Dr. Gary Shipley of Cascade Biologics for providing the melanocyte lines HeMn-LP and HeMn-MP used in this study.

\section{Author details}

'Department of Medicine, Division of Hematology, Stanford University School of Medicine, Stanford, California, USA. ${ }^{2}$ Department of Pathology, Stanford University School of Medicine, Stanford, California, USA. ${ }^{3}$ Moffitt Cancer Center, Tampa, Florida, USA.

\section{Authors' contributions}

GYC carried out the biochemical studies, immunoassays, participated in the statistical analysis, discussion of results and drafted the manuscript. HEK carried out the immunoassays, participated in the discussion of results and drafted the manuscript. TBS coordinated the pre-testing experiments, contributed to the refinement of experiment protocol and participated in the discussion of results. EJS performed the immunohistochemistry. JSW selected the donors for the study. PPL conceived the study, participated in its design and coordination and drafted the manuscript. All authors read and approved the final manuscript.

\section{Competing interests}

The authors declare that they have no competing interests.

Received: 29 April 2011 Accepted: 27 July 2011 Published: 27 July 2011

\section{References}

1. Hodi FS, O'Day SJ, McDermott DF, Weber RW, Sosman JA, Haanen JB, Gonzalez R, Robert C, Schadendorf D, Hassel JC, Akerley W, van den Eertwegh AJ, Lutzky J, Lorigan P, Vaubel JM, Linette GP, Hogg D, Ottensmeier CH, Lebbé C, Peschel C, Quirt I, Clark JI, Wolchok JD, Weber JS, Tian J, Yellin MJ, Nichol GM, Hoos A, Urba WJ: Improved survival with ipilimumab in patients with metastatic melanoma. N Engl J Med 2010, 363:711-723.

2. Dudley ME, Yang JC, Sherry R, Hughes MS, Royal R, Kammula U, Robbins PF, Huang J, Citrin DE, Leitman SF, Wunderlich J, Restifo NP, Thomasian A, Downey SG, Smith FO, Klapper J, Morton K, Laurencot C, White DE, Rosenberg SA: Adoptive cell therapy for patients with metastatic melanoma: evaluation of intensive myeloablative chemoradiation preparative regimens. J Clin Oncol 2008, 26:5233-5239.

3. Yee C, Thompson JA, Roche P, Byrd DR, Lee PP, Piepkorn M, Kenyon K, Davis MM, Riddell SR, Greenberg PD: Melanocyte destruction after antigen-specific immunotherapy of melanoma: direct evidence of $t$ cellmediated vitiligo. J Exp Med 2000, 192:1637-1644.

4. Garbelli S, Mantovani S, Palermo B, Giachino C: Melanocyte-specific, cytotoxic T cell responses in vitiligo: the effective variant of melanoma immunity? Pigment Cell Res 2005, 18:234-242.

5. Wankowicz-Kalinska A, Le Poole C, van den Wijngaard R, Storkus WJ, Das PK: Melanocyte-specific immune response in melanoma and vitiligo: two faces of the same coin? Pigment Cell Res 2003, 16:254-260

6. Palmer DC, Chan CC, Gattinoni L, Wrzesinski C, Paulos CM, Hinrichs CS, Powell DJ Jr, Klebanoff CA, Finkelstein SE, Fariss RN, Yu Z, Nussenblatt RB, Rosenberg SA, Restifo NP: Effective tumor treatment targeting a melanoma/melanocyte-associated antigen triggers severe ocular autoimmunity. Proc Natl Acad Sci USA 2008, 105:8061-8066.

7. Bouwhuis MG, Ten Hagen TL, Suciu S, Eggermont AM: Autoimmunity and treatment outcome in melanoma. Curr Opin Oncol 2011, 23:170-176.

8. Rosenberg SA, Kawakami Y, Robbins PF, Wang R: Identification of the genes encoding cancer antigens: implications for cancer immunotherapy. Adv Cancer Res 1996, 70:145-177. 
9. Boon T: Tumor antigens recognized by cytolytic T lymphocytes: present perspectives for specific immunotherapy. Int J Cancer 1993, 54:177-180.

10. Kawakami Y, Robbins PF, Wang RF, Parkhurst M, Kang X, Rosenberg SA: The use of melanosomal proteins in the immunotherapy of melanoma. $J$ Immunother 1998, 21:237-246.

11. Okamoto T, Irie RF, Fujii S, Huang SK, Nizze AJ, Morton DL, Hoon DS: Antityrosinase-related protein-2 immune response in vitiligo patients and melanoma patients receiving active-specific immunotherapy. J Invest Dermatol 1998, 111:1034-1039.

12. Guevara-Patino JA, Turk MJ, Wolchok JD, Houghton AN: Immunity to cancer through immune recognition of altered self: studies with melanoma. Adv Cancer Res 2003, 90:157-177.

13. Morgan DJ, Kreuwel HT, Fleck S, Levitsky HI, Pardoll DM, Sherman LA: Activation of low avidity CTL specific for a self epitope results in tumor rejection but not autoimmunity. J Immunol 1998, 160:643-651.

14. Betts MR, Brenchley JM, Price DA, De Rosa SC, Douek DC, Roederer M, Koup RA: Sensitive and viable identification of antigen-specific CD8+ T cells by a flow cytometric assay for degranulation. $J$ Immunol Methods 2003, 281:65-78.

15. Kohrt HE, Shu CT, Stuge TB, Holmes SP, Weber J, Lee PP: Rapid assessment of recognition efficiency and functional capacity of antigen-specific T-cell responses. J Immunother 2005, 28:297-305.

16. Rubio V, Stuge TB, Singh N, Betts MR, Weber JS, Roederer M, Lee PP: Ex vivo identification, isolation and analysis of tumor-cytolytic T cells. Nat Med 2003, 9:1377-1382.

17. Stuge TB, Holmes SP, Saharan S, Tuettenberg A, Roederer M, Weber JS, Lee PP: Diversity and recognition efficiency of $\mathrm{T}$ cell responses to cancer. PLoS Med 2004, 1:e28.

18. Chomczynski P, Sacchi N: Single-step method of RNA isolation by acid guanidinium thiocyanate-phenol-chloroform extraction. Anal Biochem 1987, 162:156-159.

19. Jungbluth AA, Iversen K, Coplan K, Williamson B, Chen YT, Stockert E, Old LJ, Busam KJ: Expression of melanocyte-associated markers gp-100 and Melan-A/MART-1 in angiomyolipomas. An immunohistochemical and rt-PCR analysis. Virchows Arch 1999, 434:429-435.

20. Carrabba MG, Castelli C, Maeurer MJ, Squarcina P, Cova A, Pilla L, Renkvist N, Parmiani G, Rivoltini L: Suboptimal activation of CD8(+) T cells by melanoma-derived altered peptide ligands: role of Melan-A/MART-1 optimized analogues. Cancer Res 2003, 63:1560-1567.

21. Yee C, Savage PA, Lee PP, Davis MM, Greenberg PD: Isolation of high avidity melanoma-reactive CTL from heterogeneous populations using peptide-MHC tetramers. J Immunol 1999, 162:2227-2234

22. Gogas H, loannovich J, Dafni U, Stavropoulou-Giokas C, Frangia K, Tsoutsos D, Panagiotou P, Polyzos A, Papadopoulos O, Stratigos A, et al: Prognostic significance of autoimmunity during treatment of melanoma with interferon. N Engl I Med 2006, 354:709-718.

23. Nordlund JJ, Kirkwood JM, Forget BM, Milton G, Albert DM, Lerner AB: Vitiligo in patients with metastatic melanoma: a good prognostic sign. J Am Acad Dermatol 1983, 9:689-696.

24. Bystryn JC, Rigel D, Friedman RJ, Kopf A: Prognostic significance of hypopigmentation in malignant melanoma. Arch Dermatol 1987, 123:1053-1055

25. Boasberg PD, Hoon DS, Piro LD, Martin MA, Fujimoto A, Kristedja TS, Bhachu S, Ye X, Deck RR, O'Day SJ: Enhanced survival associated with vitiligo expression during maintenance biotherapy for metastatic melanoma. J Invest Dermatol 2006, 126:2658-2663.

26. Le Gal FA, Avril MF, Bosq J, Lefebvre P, Deschemin JC, Andrieu M, Dore MX, Guillet JG: Direct evidence to support the role of antigen-specific CD8(+) T cells in melanoma-associated vitiligo. J Invest Dermatol 2001, 117:1464-1470

27. Rubio-Godoy V, Dutoit V, Rimoldi D, Lienard D, Lejeune F, Speiser D, Guillaume P, Cerottini JC, Romero P, Valmori D: Discrepancy between ELISPOT IFN-gamma secretion and binding of A2/peptide multimers to TCR reveals interclonal dissociation of CTL effector function from TCRpeptide/MHC complexes half-life. Proc Natl Acad Sci USA 2001, 98:10302-10307.

28. Schallreuter KU, Levenig C, Berger J: Vitiligo and cutaneous melanoma. A case study. Dermatologica 1991, 183:239-245.

29. Steitz J, Bruck J, Lenz J, Buchs S, Tuting T: Peripheral CD8+ T cell tolerance against melanocytic self-antigens in the skin is regulated in two steps by CD4+ T cells and local inflammation: implications for the pathophysiology of vitiligo. J Invest Dermatol 2005, 124:144-150.

30. Jacobs JF, Aarntzen EH, Sibelt LA, Blokx WA, Boullart AC, Gerritsen MJ, Hoogerbrugge PM, Figdor CG, Adema GJ, Punt CJ, de Vries IJ: Vaccinespecific local $T$ cell reactivity in immunotherapy-associated vitiligo in melanoma patients. Cancer Immunol Immunother 2009, 58:145-151.

31. Rivoltini L, Barracchini KC, Viggiano V, Kawakami Y, Smith A, Mixon A, Restifo NP, Topalian SL, Simonis TB, Rosenberg SA, Marincola FM: Quantitative correlation between HLA class I allele expression and recognition of melanoma cells by antigen-specific cytotoxic $T$ lymphocytes. Cancer Res 1995, 55:3149-3157.

32. Lethe $B$, van der Bruggen $P$, Brasseur F, Boon T: MAGE-1 expression threshold for the lysis of melanoma cell lines by a specific cytotoxic $T$ lymphocyte. Melanoma Res 1997, 7(Suppl 2):S83-88.

33. Riker Al, Kammula US, Panelli MC, Wang E, Ohnmacht GA, Steinberg SM, Rosenberg SA, Marincola FM: Threshold levels of gene expression of the melanoma antigen gp100 correlate with tumor cell recognition by cytotoxic T lymphocytes. Int I Cancer 2000, 86:818-826.

34. Barrow C, Browning J, MacGregor D, Davis ID, Sturrock S, Jungbluth AA, Cebon J: Tumor antigen expression in melanoma varies according to antigen and stage. Clin Cancer Res 2006, 12:764-771.

35. Murer K, Urosevic M, Willers J, Selvam P, Laine E, Burg G, Dummer R: Expression of Melan-A/MART-1 in primary melanoma cell cultures has prognostic implication in metastatic melanoma patients. Melanoma Res 2004, 14:257-262.

36. Urosevic M, Braun B, Willers J, Burg G, Dummer R: Expression of melanoma-associated antigens in melanoma cell cultures. Exp Dermato 2005, 14:491-497.

37. Khong HT, Wang QJ, Rosenberg SA: Identification of multiple antigens recognized by tumor-infiltrating lymphocytes from a single patient: tumor escape by antigen loss and loss of MHC expression. J Immunother 2004, 27:184-190.

38. Durda PJ, Dunn IS, Rose LB, Butera D, Benson EM, Pandolfi F, Kurnick JT: Induction of "antigen silencing" in melanomas by oncostatin M: downmodulation of melanocyte antigen expression. Mol Cancer Res 2003, 1:411-419.

39. Kurnick JT, Ramirez-Montagut T, Boyle LA, Andrews DM, Pandolfi F, Durda PJ, Butera D, Dunn IS, Benson EM, Gobin SJ, van den Elsen PJ: A novel autocrine pathway of tumor escape from immune recognition: melanoma cell lines produce a soluble protein that diminishes expression of the gene encoding the melanocyte lineage melan- $\mathrm{A} /$ MART-1 antigen through down-modulation of its promoter. J Immunol 2001, 167:1204-1211.

40. Maeurer MJ, Gollin SM, Storkus WJ, Swaney W, Karbach J, Martin D, Castelli C, Salter R, Knuth A, Lotze MT: Tumor escape from immune recognition: loss of HLA-A2 melanoma cell surface expression is associated with a complex rearrangement of the short arm of chromosome 6. Clin Cancer Res 1996, 2:641-652.

doi:10.1186/1479-5876-9-122

Cite this article as: Chang et al:: Cytotoxic T lymphocyte responses against melanocytes and melanoma. Journal of Translational Medicine 2011 9:122.

\section{Submit your next manuscript to BioMed Central and take full advantage of:}

- Convenient online submission

- Thorough peer review

- No space constraints or color figure charges

- Immediate publication on acceptance

- Inclusion in PubMed, CAS, Scopus and Google Scholar

- Research which is freely available for redistribution 